Carlos A. Osella
Hugo D. Sánchez $^{\text {a }}$
Carlos R. Carrara $^{\text {a }}$
Marisa A. de la Torre
M. Pilar Buera

a Instituto Tecnología de
Alimentos,
Facultad de Ingeniería Química,
Universidad Nacional del Litoral,
Santa Fe, Argentina
b Departamento de Industrias,
Facultad de Ciencias Exactas y
Naturales,
Universidad de Buenos Aires,
Buenos Aires, Argentina

\section{Water Redistribution and Structural Changes of Starch During Storage of a Gluten-free Bread}

\begin{abstract}
The objective of the present work was to analyze molecular and supramolecular changes of bread starch and to relate bread firmness increase during storage with starch recrystallization and water hydration levels and migration in gluten-free bread. At the studied conditions starch was in the supercooled region of the state diagram, at a temperature between $T_{\mathrm{g}}$ (glass transition temperature) and $T_{\mathrm{m}}$ (melting temperature), feasible to crystallize. The crystalline degree during storage was followed by the intensity increase in the $\mathrm{X}$-ray diffraction peaks. During bread storage, water migration occurred from the crumb towards the crust. Water amount and redistribution affected the kind of starch crystallites formed and firmness of aged bread. It was not the total amount of crystalline fraction that determined bread firmness, but the type of crystallites formed. These observations are a further evidence that bread firmness development and starch recrystallization, although being related phenomena, are obviously separate events.
\end{abstract}

Keywords: Starch crystallinity; Gluten-free bread; Water redistribution

\section{Introduction}

Aging of starch-based products leads to the loss of adequate quality characteristics due to changes in texture and flavor. Although it has been studied for more than a century and a half, bread staling is still not fully understood and it is responsible for economic losses both for the baking industry and for the consumer.

Bread is an unstable, elastic, solid foam, the solid part of which contains a continuous phase composed of an elastic network of cross-linked gluten molecules and leached starch polymer molecules, primarily amylose (complexed or not with polar lipid molecules), and a discontinuous phase of entrapped, partially gelatinized, swollen, deformed starch granules [1] .

Starch, being present in a higher proportion than gluten, plays an important role in forming the matrix during bread cooking and promotes aging upon its storage. However, structural stability of bread is significantly controlled by gluten (part of the continuous phase) [2]. Gluten-free breads elaborated with different starches age very fast [3]. Extensive information on bread staling has been obtained by X-ray diffraction analysis of starch, which provides information about the crystalline structure. Immediately after baking, the starch in bread has an amorphous structure, but the crystalline pattern is slowly recovered

Correspondence: M. Pilar Buera, Departamento de Industrias, Facultad de Ciencias Exactas y Naturales, Universidad de Buenos Aires, Buenos Aires, Argentina. Fax +54-11-4576-3366. e-mail pilar@di.fcen.uba.ar. during storage; this transition is called retrogradation. Native starches may show an "A" or "B" diffraction pattern, according to their origin. However, once they are gelatinized, they all develop a "B"-type diffraction pattern during aging [4]. The diffraction pattern is also dependent on the amount of water present. Samples with water content higher than $43 \%$ developed "B"-type patterns and those of a water content lower than $29 \%$ developed "A"-type patterns. An estimation of the relative amounts of crystalline and amorphous phases may also be obtained by analyzing simultaneously the peaks corresponding to the crystalline phase and the background produced by the amorphous phase [5].

The high viscosity of the gel formed upon heating and cooling plays an important role restricting the molecular mobility of starch polymers, delaying their reordering and thus affecting the kinetics of starch retrogradation [6]. The viscosity of these systems depends on the difference between the temperature of the system and the glass transition temperature, $T_{\mathrm{g}}$ [7]. The glass temperature of baked products is a function of the composition of the system (mainly gluten and starch) and is highly modified by the amount of water and small solutes [8]. The thermal transitions occurring during cooking of breads and their storage have profound influence on structural characteristics [9].

Though the changes in firmness of starch-based products have been extensively studied, the mechanisms of such changes have not been fully defined. It is known, however, that the mobility of water plays an important role [10]. 
The objective of the present work was to analyze molecular, microscopic and supramolecular changes of bread starch in gluten-free bread and to relate firmness increase during storage with starch recrystallization and water hydration levels and migration.

\section{Materials and Methods}

\subsection{Bread making}

Raw materials used were: corn starch [14.4\% water, $0.20 \%$ protein; onset of gelatinization temperature $\left(T_{\text {gelo }}\right)$ range: $68-74^{\circ} \mathrm{C}$ ] from Industrias de Maíz S.A., Buenos Aires, Argentina; cassava starch [14.3\% water, $0.08 \%$ protein, $T_{\text {gelo }}$ range: $60-67^{\circ} \mathrm{C}$ ] from Cooperativa Agrícola Industrial San Alberto Ltda., Misiones, Argentina; rice flour [13.7\% water, $6.0 \%$ protein, $T_{\text {gelo }}$ range: $68-75^{\circ} \mathrm{C}$ ] from Atilio Betella y Cía, Santa Fe, Argentina. Protein content was calculated as $\%$ nitrogen $\times 5.7$. An oleomargarine (OPTIMA, from Molinos Río de la Plata S.A., Buenos Aires, Argentina) with melting point $36^{\circ} \mathrm{C}$, was used. The premix, containing gum, sucrose, and salt, was developed by Instituto de Tecnologia de AlimentosFacultad de Ingenieria Quimica-Universidad Nacional del Litoral, Santa Fe, Argentina (in patent process).

Bread was made according to the baking test for bread without gluten proposed by Sánchez et al. [12]. Solid ingredients (corn starch, $315 \mathrm{~g}$; rice flour, $90 \mathrm{~g}$; cassava starch, $45 \mathrm{~g}$; fat, $45 \mathrm{~g}$; premix, $46.5 \mathrm{~g}$; yeast, $45 \mathrm{~g}$ ) were mixed. Water was then added at different proportions (Tab. 1) and the formulations A, B, C or D obtained were mixed at $400 \mathrm{rpm}$ for $1 \mathrm{~min}$ and $600 \mathrm{rpm}$ for $2 \mathrm{~min}$. A General Electric mixer with two stainless steel whisks at 400 and $600 \mathrm{rpm}$ was employed.

A sample of the resulting batter $(250 \mathrm{~g})$ was placed in a greased bread pan and proofed at $27^{\circ} \mathrm{C}$ and $80 \%$ humidity, controlling the rising with a push-meter (a rise from 15 to $30 \mathrm{~mm}$ for $25 \mathrm{~g}$ of batter). The proofing box allowed temperature and humidity control and was from DALVO,
Ojalvo S.A., Santa Fe, Argentina. The apparatus used for proofing control was a push-meter consisting of a glass cylinder (75 mm height, $45 \mathrm{~mm}$ i. d.) with a tight-fitting plastic piston, that rises during proofing.

Bread was then baked at $210^{\circ} \mathrm{C}$ for $40 \mathrm{~min}$ without steam. The oven (DALVO, Ojalvo S.A., Santa Fe, Argentina) had electrical heating and temperature control up to $300^{\circ} \mathrm{C}$.

After baking, each loaf of bread was packed in a sealed polyethylene bag with the crust intact and stored at $30^{\circ} \mathrm{C}$. Three replicates from each different loaf were used for each experiment.

\subsection{Measurement of batter consistency}

Batter consistency was measured as softness at the end of mixing using a SETA cone penetrometer (StanhopeSeta Limited, Surrey, England). fitted with a flat-nosed cone (greater diameter: $3.2 \mathrm{~cm}$; smaller diameter: $1.1 \mathrm{~cm}$; length: $2.5 \mathrm{~cm}$; weight: $55.0 \mathrm{~g}$ ). Displacement in the batter was measured at $3 \mathrm{~s}$ (range 0-400 units, equivalent to 0$40 \mathrm{~mm}$ penetration). The measurement range was $0-400$ penetration units (P. U.). Higher penetration units indicate increased batter softness.

\subsection{Volume measurement and bread scoring}

Breads were evaluated $1 \mathrm{~h}$ after baking. Loaf volume was determined on three replicates from each different loaf by rapeseed displacement. Sensory analysis of bread (bread score) was done by an expert panel of three, each of whom had more than 20 years baking experience. Samples were served as slices at the same time. Each expert scored each sample once. As recommended by Pyler [11], parameters evaluated and maximum scores were: specific volume, 15 (regarding to $5 \mathrm{~mL} / \mathrm{g}$ ); crust, 15 (color and thickness); texture, 15 (elasticity, stickiness); crumb color, 10 (cream white as better); crumb grain, 10 (alveolus size and shape); aroma, 15 (fresh bread like); and taste, 20 (flavor and mouth feeling) [12].

Tab. 1. Composition of batters.

\begin{tabular}{llllll}
\hline $\begin{array}{l}\text { Formu- } \\
\text { lation }\end{array}$ & $\begin{array}{l}\text { Water } \\
\text { added } \\
{[\mathrm{mL}](1)}\end{array}$ & $\begin{array}{l}\text { Corn starch }+ \\
\text { rice flour }+ \\
\text { cassava } \\
\text { starch }[\mathrm{g}](2)\end{array}$ & $\begin{array}{l}\text { Water } \\
\text { added } \\
{[\%]} \\
(1) /(2)\end{array}$ & $\begin{array}{l}\text { Weight of all } \\
\text { solid } \\
\text { components* } \\
{ }^{*}[\mathrm{~g}](3)\end{array}$ & $\begin{array}{l}\text { Percentage of corn starch } \\
+ \text { rice flour }+ \text { cassava } \\
\text { starch related to batter } \\
(2) /(3)\end{array}$ \\
\hline A & 270 & 450 & 60 & 586.5 & 52.6 \\
B & 315 & 450 & 70 & 586.5 & 50.0 \\
C & 450 & 450 & 100 & 586.5 & 43.5 \\
D & 675 & 450 & 150 & 586.5 & 35.7 \\
\hline
\end{tabular}

${ }^{\star}$ Components in column (2) $+45 \mathrm{~g}$ fat $+46.5 \mathrm{~g}$ premix $+45 \mathrm{~g}$ yeast. 


\subsection{Water content and water activity of breads}

Ten millimeters of crust were removed over the whole loaf surface in order to separate crumb. Water contents of crust and bread crumb were determined using a two-step method (AACC 48-18, 1983). Water content and water activity $\left(a_{\mathrm{w}}\right)$ of bread crumb were measured $1 \mathrm{~h}$ after baking, when the crumb temperature had decreased to $28^{\circ} \mathrm{C}$. Water activity was determined by an Aqua lab model CX3 (Decagon Devices, Pullman, Washington).

\subsection{Thermal transitions}

Thermal transitions of the different bread crumbs were determined by differential scanning calorimetry (DSC) using a Mettler 822 system with TC 15 TA processor, DSC 30 measuring cell, and STAR ${ }^{\circledR}$ Thermal Analysis System version 3.1 software (Mettler Toledo AG, Greifensee, Switzerland).

The instrument was calibrated using zinc, lead and indium as standards. All measurements were made at a scanning rate of $5^{\circ} \mathrm{C} / \mathrm{min}$ using hermetically sealed aluminum pans of $40 \mu \mathrm{L}$ capacity. Duplicate samples of the crumbs after one day of storage were scanned from at least $40^{\circ} \mathrm{C}$ below to at least $40^{\circ} \mathrm{C}$ above the glass transition temperature. An immediate rescan was run for each sample to verify the endothermic baseline shift associated with the glass transition. The temperature of the change in heat capacity was considered as the glass transition temperature $\left(T_{\mathrm{g}}\right)$. The samples were then scanned up to $120^{\circ} \mathrm{C}$ to detect the temperature of the melting peak $\left(T_{\mathrm{m}}\right)$ due to starch retrogradation. An empty aluminum pan was used as a reference.

\subsection{X-Ray diffractometry}

X-ray diffraction patterns of the starches and rice flour, before and after baking were obtained with a Shimadzu DX - 1 diffractometer equipped with a monochromator, that selects the $\mathrm{K}_{\alpha}$ radiation from a copper target generated under $30 \mathrm{kV}$ and $40 \mathrm{~mA}$. Patterns were recorded from diffraction angles $(2 \Theta)$ of $5-30^{\circ}$ at a scan speed of $0.5^{\circ}$ min. The X-ray diffraction patterns of the starches and rice flour before baking were measured at their corresponding moisture content.

Crumb was dried in a convection-forced air oven at $35^{\circ} \mathrm{C}$ to $12-14 \%$ of water content (similar to that of the native starches). The drying temperature was selected in order to avoid annealing effects $[13,14]$. The dried crumb samples were milled in a laboratory mill and passed through a 100 mesh sieve.
The crystallinity of each peak, mainly at 17 and $20^{\circ}$, was measured as follows: the whole diffractogram was carefully cut out and then cut again to isolate the two areas. The upper sections were weighed and the areas were calculated by comparison of their weight of known areas prepared using the same paper [15].

\subsection{Crumb texture}

The firmness of bread crumb was measured according to Baik and Chinachoti [16] using a universal testing machine (Shimadzu). The bread crumb $(25 \times 25 \times 25 \mathrm{~mm})$ was uniaxially compressed from 25 to $20 \mathrm{~mm}$ in height to measure force at $20 \%$ deformation. The diameter of the cylindrical plunger was $100 \mathrm{~mm}$ and the cross-head speed was $10 \mathrm{~mm} / \mathrm{min}$.

\section{Results and Discussion}

Tab. 2 shows the results of batter consistency, specific volume measurements and bread score of breads prepared with the different formulations. Fig. 1 shows their visual aspect. When baked with $60 \%$ water (formulation A), the specific volume of the bread was low because the batter had a high viscosity, offering a high resistance to bubble expansion during fermentation. When the amount of water added was increased to $70 \%$ (formulation B), the batter consistency decreased and the specific volume increased. However, the specific volume and bread score decreased for formulations $C$ and $D$, with more $(100 \%$ and $150 \%$ ) water added. When the water amount that the hydrocolloids could absorb was surpassed [17, 18], the excess water promoted a dramatic decrease of viscosity and an increase in the batter consistency. The matrix was not capable of retaining the gas formed during fermentation and alveolar collapse occurred, as shown in Fig. 1.

Tab. 2. Batter consistency, bread volume and bread score.

\begin{tabular}{lllll}
\hline & \multicolumn{4}{c}{ Formulation } \\
& A & B & C & D \\
\hline Batter consistency [P.U. ] & 105 & 200 & 260 & 360 \\
Specific volume [mL/g] & 4.19 & 4.84 & 3.32 & 1.78 \\
Bread score (max. 100) & 81 & 93 & 68 & 30 \\
\hline
\end{tabular}

Water activity, moisture content and the temperatures of the thermal transitions of the crumbs $1 \mathrm{~h}$ after baking are shown in Fig. 2. The water content and water activity of the bread crumb increased with increasing water content of the original batter. However, the effects of water con- 


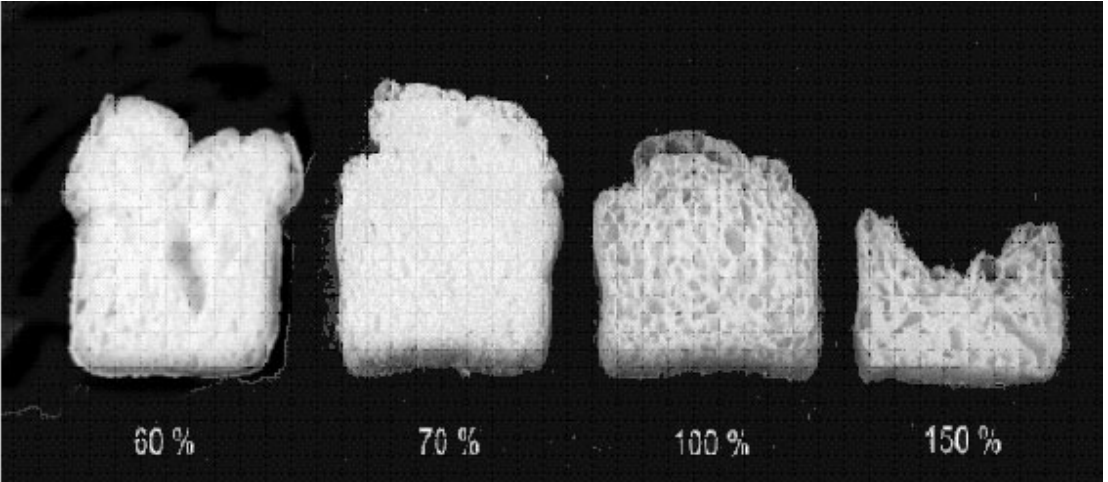

Fig. 1. Breads obtained with 60,70 , 100 and $150 \%$ of water added respect to corn starch + rice flour + cassava starch. tent of the batter were not sensitively reflected on the corresponding glass transition and melting temperature values of the loaves (Fig. 2). The obtained $T_{\mathrm{g}}$ values agree with those reported by Le Meste et al. [17]. At water contents corresponding to the analyzed samples (between 40 to $65 \%$ ), the curves of $T_{\mathrm{g}}$ and $T_{\mathrm{m}}$ of white bread showed a typically flattened shape when plotted vs. water content and this is related to the maximum plasticizing effect, that can be performed by water on starch $[17,18]$. Starch recrystallization in the baked samples is feasible in the supercooled region of the state diagram, which corresponds to temperatures between $T_{\mathrm{g}}$ and $T_{\mathrm{m}}[1,8,17]$. In order to analyze starch recrystallization in the baked loaves, a storage temperature of $30^{\circ} \mathrm{C}$ was chosen, which is in the middle region between $T_{\mathrm{g}}$ and $T_{\mathrm{m}}$, as Fig. 2 shows. This is a quite high temperature for food storage, but it would correspond to a non-refrigerated storage during the summer season in temperate and subtropical regions.

Fig. 3a shows the changes in $a_{w}$ of the bread crumbs during storage at $30^{\circ} \mathrm{C}$ in closed containers for 7 days. Water activity was maintained at an almost constant level

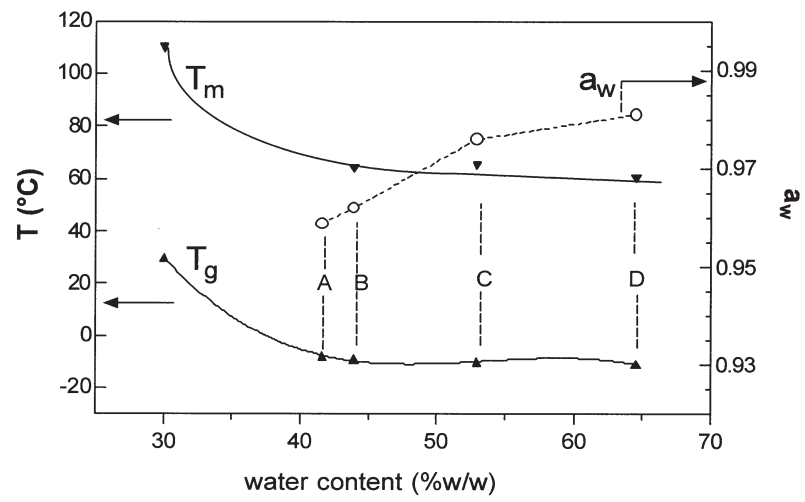

Fig. 2. Water activity and moisture content values and the temperatures of the onset of the glass transition $\left(T_{\mathrm{g}}\right)$ and of the peak of melting $\left(T_{\mathrm{m}}\right)$ of the bread crumb of the different formulations measured $1 \mathrm{~h}$ after baking. during days 0 and 1 . At the seventh day there was a decrease of the $a_{w}$ values for all the formulations. The difference in the $a_{w}$ values between days 1 and 7 was only about $0.04 a_{\mathrm{w}}$ units in all cases, while the corresponding differences in water content were about $10 \%$.

Figs. $3 b$ and $3 c$ show the changes in the water content of the crumbs and the crusts, respectively, during storage at $30^{\circ} \mathrm{C}$. The water content gradually increased in the crust while it decreased in the crumb.

Fig. 4a shows X-ray diffractrograms of a mixture of corn starch and crystalline sucrose. The four peaks at the diffraction angles of $14.2,17,18$ and $23.1^{\circ}$ represent the crystalline portion of " $A$ "-pattern starch, as described in the literature $[19,20]$. Peaks marked as $A$, identified at the diffraction angles of 24.8 and $25.2^{\circ}$ correspond to crystalline sucrose. The area bellow the line joining the valleys of these peaks represent the amorphous portion [15]. Xray diffractograms of bread crumbs for the different formulations (Figs. 4 b, c, d and e) showed that the peaks of crystalline sucrose disappeared in the baked breads. The intensity of the peaks at diffraction angles of 14.2, 18 and $23.1^{\circ}$ decreased or disappeared after 7 days of storage at $30^{\circ} \mathrm{C}$, reflecting a substantial loss of " $A$ "-type crystallinity. Starch crystallinity in bread crumb (or gels) is commonly observed in the form of a "B"-structure [21]. The peak at $17^{\circ}$, characteristic of a "B"-type structure is due to the crystallization of the amorphous starch melt, mainly of the amylopectin fraction and increased during storage.

At a first stage, during baking the crystalline structure of the granule is disrupted by gelatinization (melting). When non-crystalline gels are cooled and aged, amylopectin molecules reassociate to generate a new crystalline order which has a typical X-ray diffraction pattern. The gel network is maintained by local crystalline regions, and the strength of the net depends both on the degree of molecular association and on the molecular component undergoing crystallization [20]. Starch retrogradation 

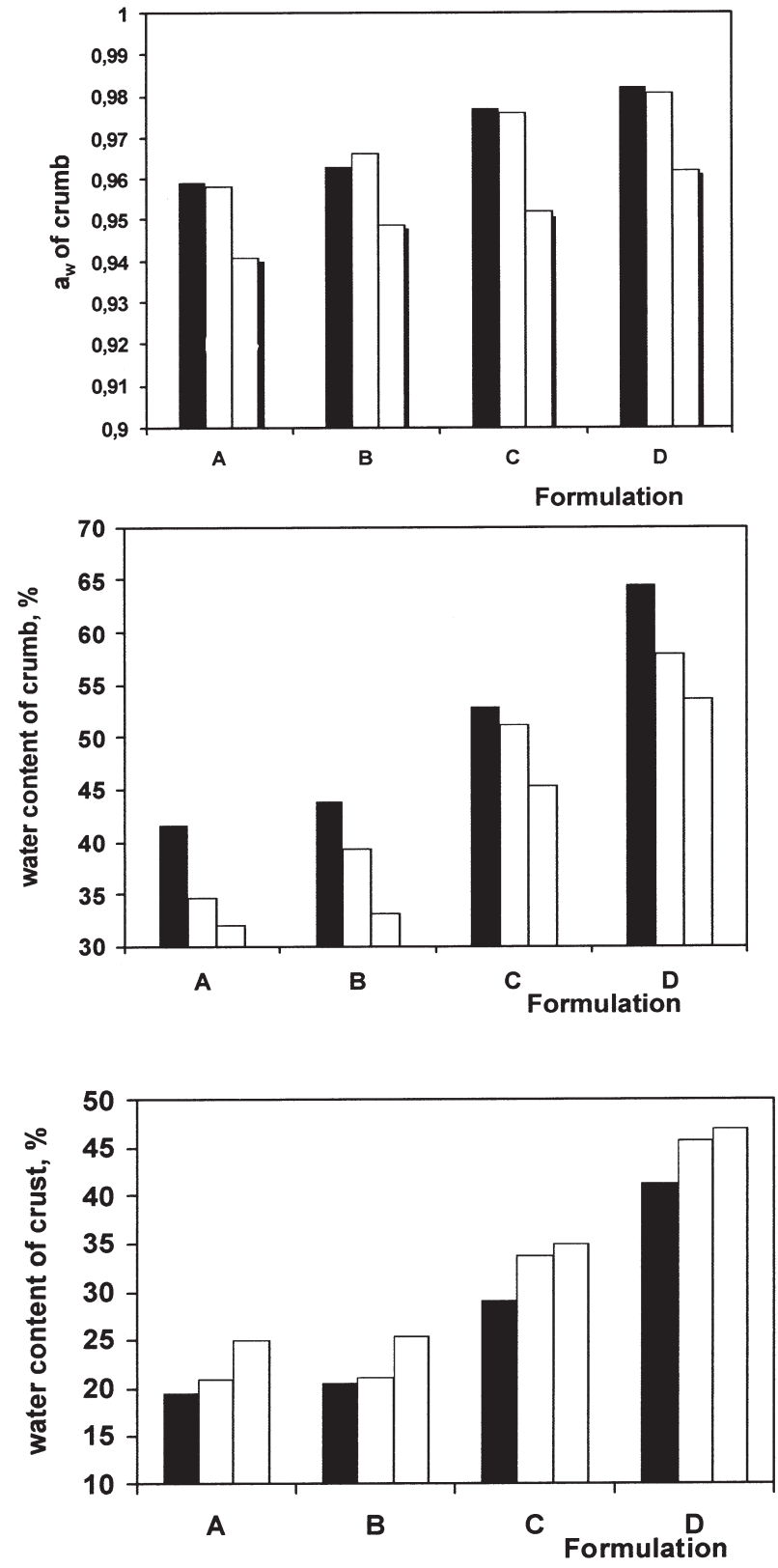

Fig. 3. a: Changes in $a_{w}$ of bread crumb during storage at $30^{\circ} \mathrm{C}$, b: Changes in water content of bread crumb during storage at $30^{\circ} \mathrm{C}$, c: Changes in water content of crust bread during storage at $30^{\circ} \mathrm{C}$.

does not only involve changes in the amylopectin fraction, but also in the amylose fraction. Amylose recrystallization is fast and occurs about $1 \mathrm{~h}$ after bread baking, during cooling, while amylopectin recrystallization is slower [4]. Amylose forms complexes with naturally occurring fatty acids and phospholipids of the granule [22], giving "V"structures (peak at $20^{\circ}$ ) [15]. The peak at $20^{\circ}$ is attributed to a well formed "V"-structure, which apparently decreased during storage.
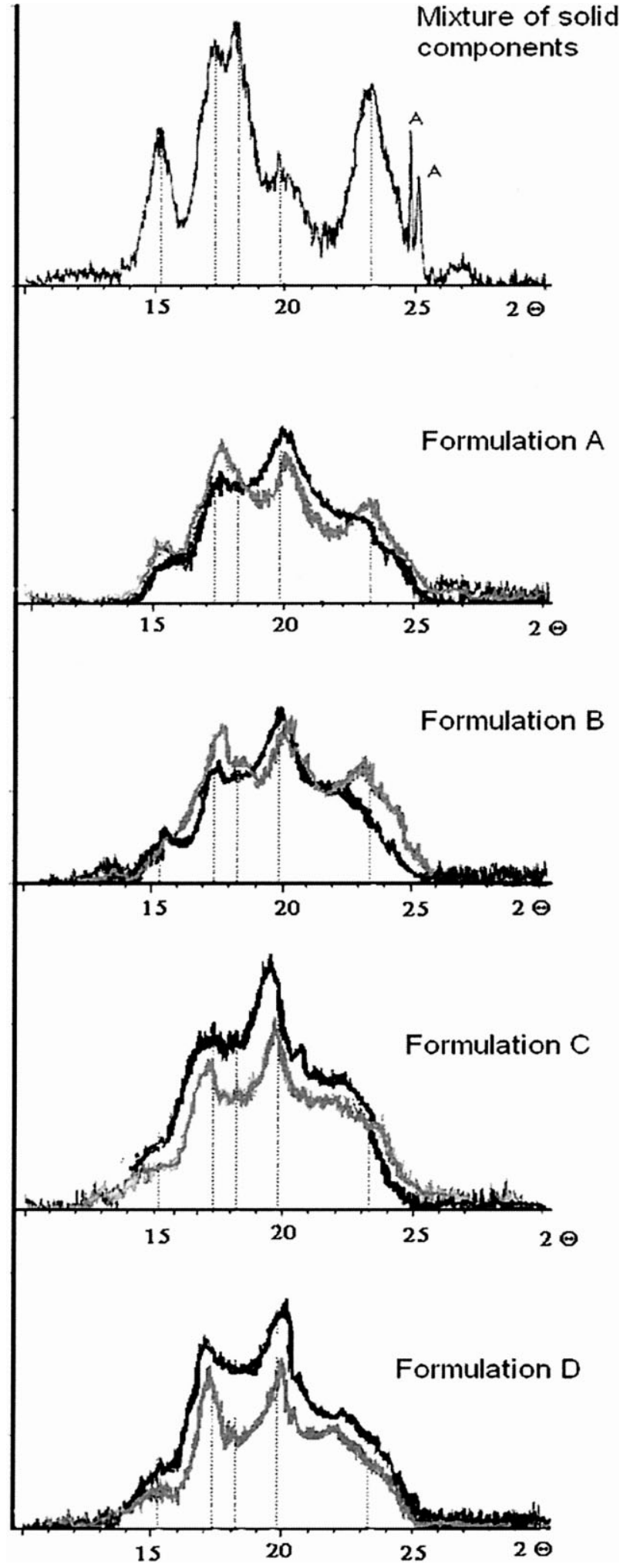

Fig. 4. a: X-ray pattern of mixture (corn starch + cassava starch + rice flour) + premix. $\mathbf{b}, \mathbf{c}, \mathbf{d}$ and $\mathbf{e}$ : X-ray pattern of bread crumbs of formulations A, B, C and D, respectively, immediately after baked and cooled and after storage at $30^{\circ} \mathrm{C}$ for 7 days. Black curves: day 0; gray curves: day 7 .

www.starch-journal.de 
The degree of crystallinity during storage may be followed by the intensity increase of the X-ray diffraction peaks (mainly that at $17^{\circ}$ ). Tab. 3 shows the degree of crystallinity (\% of total crumb crystallinity) of "B"-type structure (peak at $17^{\circ}$ ) and "V"-type structure (peak at $20^{\circ}$ ) at three different storage times for the crumbs of different formulations. The significant differences $(P \leq 0.05)$ observed show that the degree of " $B$ "-type crystallinity increased with increasing storage time and water content, while the "V"-type structure slightly decreased. A steep increase in "B"-type crystallinity observed during the first day, and the almost constant crystallinity after the first day, were also observed by Jouppila et al. [23]. Crystallization kinetics of synthetic polymers is usually modeled by the Avrami equation which can also be applied to analyze bread staling.

$\Theta=1-e^{(-k t)^{n}}$

Where:

$\Theta$ is the degree of crystallinity, $t$ is the storage time, $k$ is a constant and $n$ is the Avrami exponent, related to the kinetics of crystallization. Jouppila et al. [23] obtained the values $k=1.2 \times 10^{-1}$ and $n=1.3$ for starch recrystallization at $30{ }^{\circ} \mathrm{C}$ in breads with $60 \%$ solid content, elaborated with $60 \%$ water, after 60 min of baking. If Equation (1) is applied, the time required to obtain $50 \%$ crystallinity is:

$t_{1 / 2}=(-\ln 0.5 / k)^{1 / n}$

$t_{1 / 2}=3.85$ days.

This value corresponds to an intermediate time in the experiments shown in Tab. 3 .

As shown in Tab. 3, "V"-type structure also showed significant differences when changing the water content or the storage time. A "V" structure indicates the formation of a lipid-amylose complex during baking, which depends on the kind and amount of the complexing agent, of the water content and the heating temperature [21]. Zobel and Kulp [21] showed that type "V" crystallinity is initially low and increases during the first day of storage up to the fourth day and then remains constant. In the present work only the storage time and water content were varied, while temperature and lipid content were kept constant. It is to be noted that a transformation of the "V" to the " $\mathrm{B}$ " patterns could occur during storage, thus accounting for the decrease of "V" crystallinity.

Tab. 3. Bread crumb crystallinity, as \% of total crumb crystallinity, of "B"-type structure (diffraction peak at $17^{\circ}$ ) and "V"-type structure (diffraction peak at $20^{\circ}$ ). Variance analysis and multiple range test.

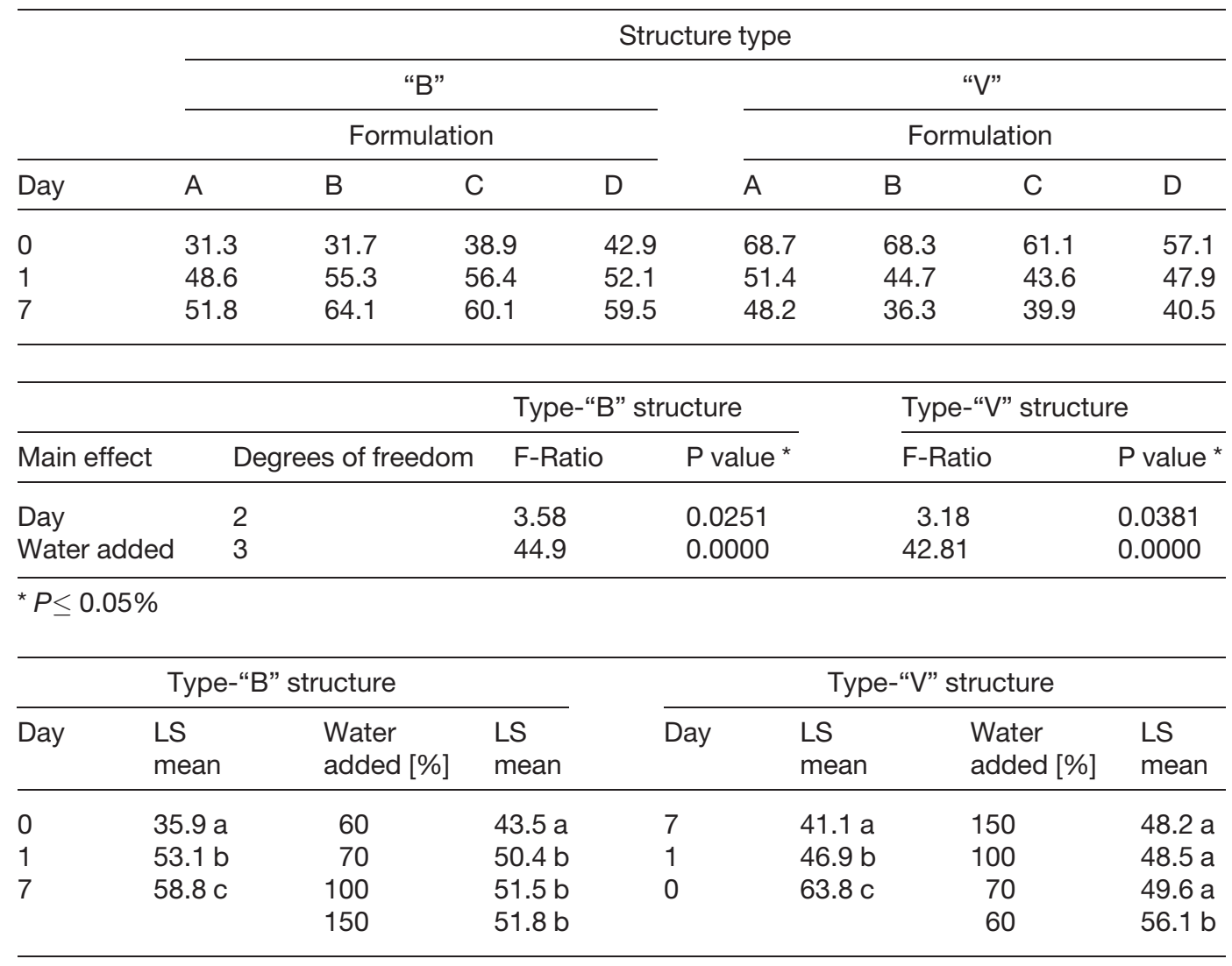


Fig. 5 shows the increase of total crystallinity ("B"+ "V") in bread crumbs during storage of the different formulations at $30^{\circ} \mathrm{C}$. Significant differences are observed for total crystallinity of crumb at different storage times $(P \leq 0.05)$. At the initial time (day 0 ) the "B" structure had a low degree of crystalline order (Tab. 3), but as storage time increased " $B$ " crystallinity increased due to amylopectin recrystallization. However, total crystallinity was not significantly affected by the different water contents of the bread formulations. Jouppila et al. [23] showed that the degree of corn starch crystallization was independent of water content and storage temperature. On the other hand, Svensson and Eliasson [24], found that the intensity of patterns "A" (for wheat starch) and "B" (for potato starch) was clearly affected by water content and temperature.

Fig. 6 represents the values of some interrelated parameters as a function of storage time and for the hydration levels 70, 100 and 150\% (formulations B, C and D). As storage time increased, the ratio between the degree of crystallization of the "B" - type structure and that of the "V" - type structure increased (Fig. 6a). Hardness of crumb, represented by the compression force at $20 \%$ deformation, also increased with storage time (Fig. 6b), while bread scoring decreased (Fig. 6c) when hydration level increased.

As shown in Fig. 1, with very low or very high hydration levels, breads of poor quality were obtained. At a hydration level of $60 \%$ (formulation A) the hardness of the crumb was extremely high, the bread crumb broke when compression forces were applied, and it was impossible to perform the measurements.

At a given value of the ratio degree of type "B" crystallinity/degree of type "V" crystallinity, the hardness of crumb was higher for the breads made with $70 \%$ hydration than for those with a higher hydration level (Fig. 7). On

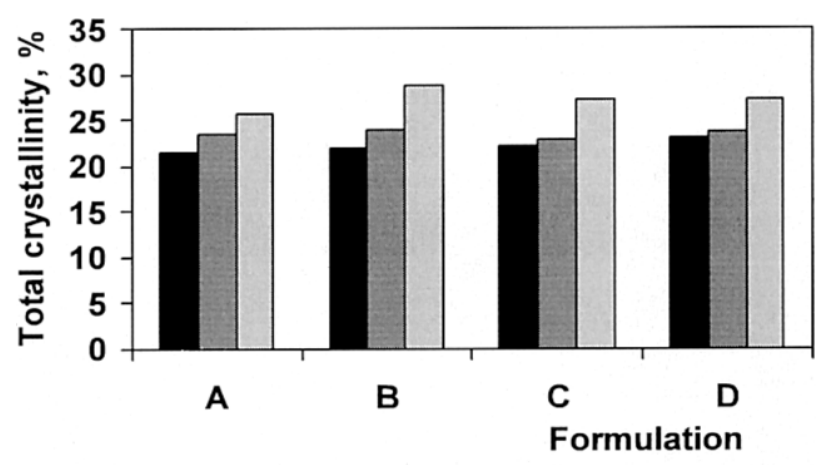

ロ Day $0 \square$ Day $1 \square$ Day 7

Fig. 5. Total crystallinity of crumb bread during storage at $30^{\circ} \mathrm{C}$.

(C) 2005 WILEY-VCH Verlag GmbH \& Co. KGaA, Weinheim

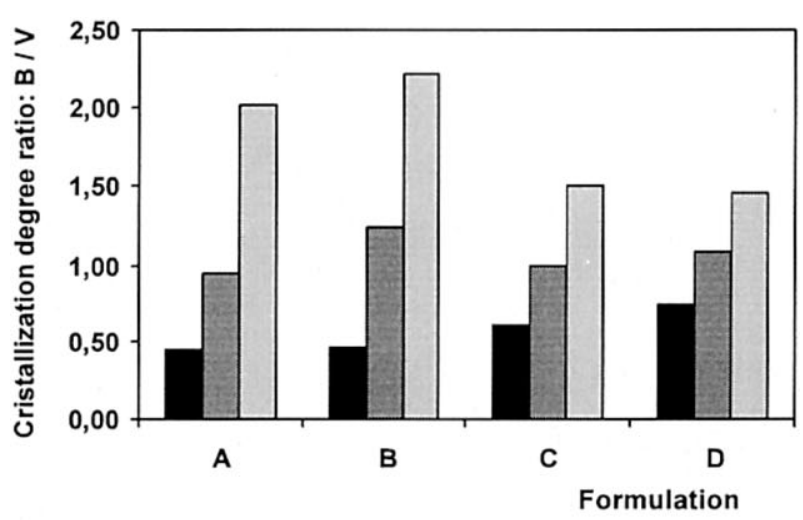

ロ Day $0 \quad \square$ Day $1 \quad \square$ Day 7

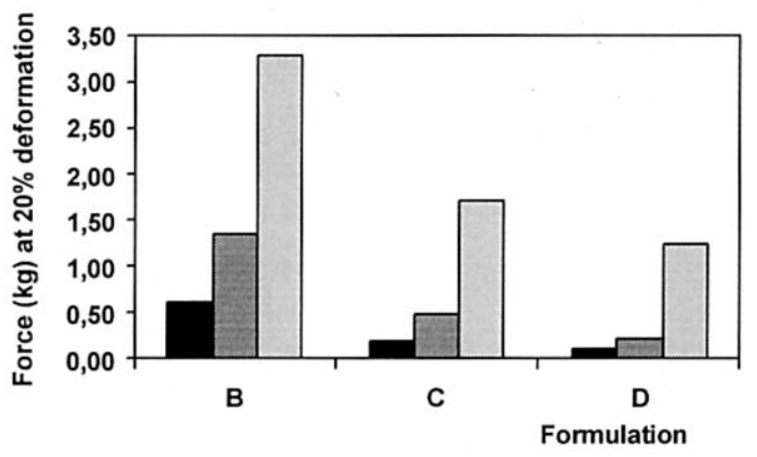

Day $0 \quad \square$ Day $1 \quad \square$ Day 7

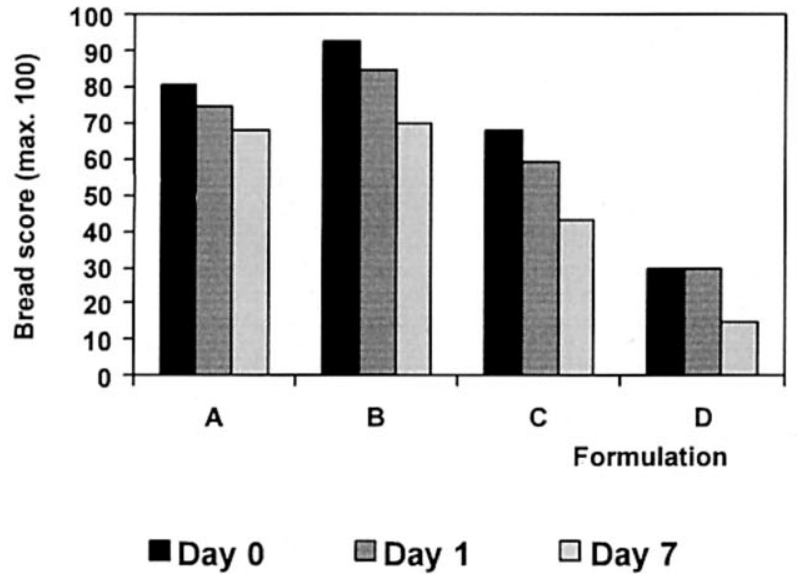

Fig. 6. a: Bread crumb crystallization degree: ratio "B"/ "V" during storage at $30^{\circ} \mathrm{C}$. b: Force [kg] at $20 \%$ deformation during storage at $30^{\circ} \mathrm{C}$. c: Bread score during storage at $30^{\circ} \mathrm{C}$. 


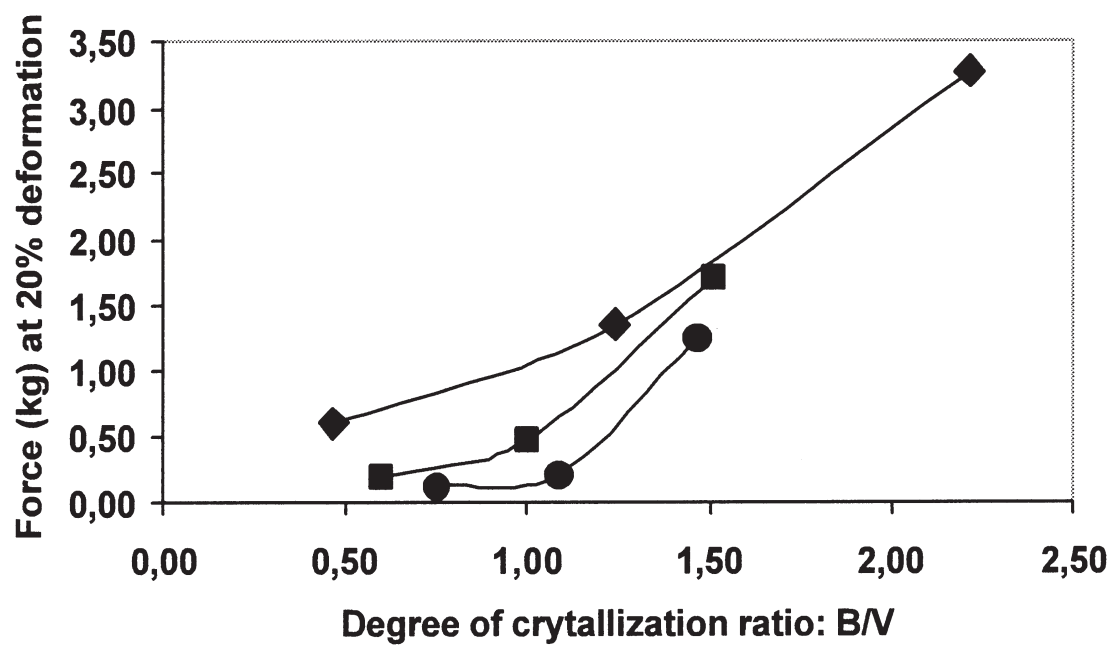

- Water added $70 \% \multimap-$ Water added $100 \%-$ Water added $150 \%$
Fig. 7. Bread crumb crystallization degree: ratio "B"/"V" vs. force [kg] at $20 \%$ deformation during storage at $30^{\circ} \mathrm{C}$. the other hand, at a given value of firmness, the ratio "B"type structure/"V"-type structure was lower for the breads made with $70 \%$ water than for those made at $100 \%$ or $150 \%$ hydration levels. Thus, water content and water redistribution during storage play an important role in determining crumb hardness. As observed in Fig. 3 (a, b and c) differences in $a_{w}$ and moisture content were observed among the samples, thus affecting the localized amylopectin recrystallization kinetics, as pointed out by Baik and Chinachoti [16].

\section{Conclusions}

The observed changes during storage of gluten-free bread involved macroscopic and supramolecular phenomena (related to the spatial order of biopolymers and to cooperative coordinated movements) and changes at molecular or microscopic levels. Firmness of bread (measured as the compression force at $20 \%$ deformation) increased in parallel to the ratio of degrees of "B"-type and "V"-type crystallites, and bread scoring consequently decreased. However, it is to be noted that, while bread firmness and bread scoring were significantly affected by the hydration level, no significant differences were observed in total crystallinity or in the recrystallization rate. The global changes reflected by X-ray diffractograms (at the molecular or microscopic levels) were less affected by water content than macroscopic changes, such as those involved in firmness development. The hydration level employed to prepare the breads, between 60 and $150 \%$, did not quantitatively affect the global rate of starch recrystallization, but had a qualitative effect, since in breads formulated with the higher hydration levels the "B"-type structure was favored.
It was not the total amount of crystalline fraction that determined bread firmness, but the type of crystallites formed. During bread storage, water migration occurred from the crumb towards the crust. Water amount and redistribution affected the kind of crystallites formed and firmness of aged bread. These observations are a further evidence that bread firmness development and starch recrystallization, although being related phenomena, are obviously separate events. To obtain a global description of the process, different methods should be employed to observe inter-related changes in bread characteristics during storage. Both qualitative and quantitative data at the molecular level are necessary to explain their macroscopic manifestations.

\section{Acknowledgments}

The authors are grateful to Eng. Victor Rozycki (ITA-FIQUNL), for providing the data adquisition and processing software. Financial support from Universidad Nacional del Litoral and Universidad de Buenos Aires, CONICET, ANPCyT (PICT 06-5066) is acknowledged.

\section{References}

[1] J. A. Gray, J. N. BeMiller: Bread staling: molecular basis and control. Comprehensive Reviews in Food Science and Food Safety. 2003, 2, 1-6.

[2] T. R. Noel, R. Parker, S. G. Ring, A. S Tatham: The glass transition behavior of wheat gluten proteins. J. Biol. Macromol. 1995, 17, 81-85.

[3] I. Defloor, M. Nys, J. A. Delcour: Wheat starch, cassava starch, and cassava flour impairment of the breadmaking potential of wheat flour. Cereal Chem. 1993, 70, 526-530. 
[4] A. Abd Karim, M. H. Norziah, C. C Seow: Methods for the study of starch retrogradation (Review). Food Chem. 2000, $71,9-36$.

[5] G. Jovanovich: Ph.D. Thesis. Universidad Nacional de La Plata, 1997.

[6] M. L. Martín, K. J. Zelesnak, R. C. Hoseney: A mechanism of bread firming. I. Role of starch swelling. Cereal Chem. 1991, $68,498-502$.

[7] H. Levine, L. Slade: Influences of glassy and rubbery states on the thermal, mechanical and structural properties of dough and baked products, in Dough Rheology and Baked Product Texture (Eds. H. Faridi, J. M. Faubion) Van Nostrand Reinhold, New York, 1990, pp. 157-300.

[8] Y. Roos, M. Karel: Water and molecular weight effects on glass transitions in amorphous carbohydrates and carbohydrate solutions. J. Food Sci. 1991, 56, 1676-1681.

[9] Y. H. Roos, M. Karel, J. L. Kokini: Glass transitions in low moisture and frozen foods: effects on shelf life and quality. Food Technol. 1996, 50, 95-100.

[10] R. Ruan, J. B. Litchfield, S. R. Eckhoff: Simultaneous nondestructive measurement of transient moisture profiles and structural changes in corn kernels during steeping using microscopic nuclear magnetic resonance imaging. Cereal Chem. 1996, 69, 600-606.

[11] E. J. Pyler, in Baking Science and Technology, Siebel Publishing Company, Chicago, 1973, pp. 891-895.

[12] H. D. Sánchez, C. A. Osella, M. A. de la Torre: Desarrollo de una fórmula para pan sin gluten. Revista de Información Tecnológica 1996, 7, 35-42.

[13] S. Nara, A. Mori, T. Komiya: Study on relative crystallinity of moist potato starch. Starch/Stärke 1978, 30, 111-114.

[14] P. Chinachoti, M. P. Steinberg: Crystallinity of sucrose by Xray diffraction as influenced by absorption versus desorption, waxy maize starch content, and water activity. J. Food Sci. 1986, 51, 456-460.
[15] H. Köksel, F. Sahbaz, Ö. Özboy: Influence of wheat-drying temperatures on the birefringence and $\mathrm{X}$-ray diffraction patterns of wet-harvested wheat starch. Cereal Chem. 1993, 70, 481-483.

[16] M. Y. Baik, P. Chinachoti: Moisture redistribution and phase transitions during bread staling. Cereal Chem. 2000, 77, 484-488.

[17] M. Le Meste, V. T. Huang, J. Panama, G. Anderson, R. Lentz: Glass transition of bread. Cereal Food World 1992, 37, 264267.

[18] M. P. Buera, K. Joupila, Y. Roos, J. Chirife: Differential scanning calorimetry glass transition temperature of white bread and mold growth in the putative glassy state. Cereal Chem. 1998, 75, 64-69.

[19] G. Arámbula Villa, J. González Hernández, C. A. Ordorica Falomir: Physicochemical, structural and textural properties of tortillas from extruded instant corn flour supplemented with various types of corn lipids. J. Cereal Sci. 2001, 33, 245-252.

[20] H. F. Zobel: Starch crystal transformations and their industrial importance. Starch/Stärke 1988, 40,1-7.

[21] H. F. Zobel, K. Kulp: The staling mechanism, in Bread Goods Freshness (Eds. R. E. Hebeda, H. F. Zobel) Marcel Dekker Inc., New York, 1996.

[22] H. F. Zobel, S. N. Young, L. A. Rocca: Starch gelatinization: an X-ray study. Cereal Chem. 1988, 65, 443-446.

[23] K. Jouppila, J. Kansikas, Y. H. Roos: Factors affecting crystallization and crystallization kinetics in amorphous corn starch. Carbohydr. Polym. 1998, 36, 143-149.

[24] E. Svensson, A. C. Eliasson: Crystalline changes in native wheat and potato starches at intermediate water levels during gelatinization. Carbohydr. Polym. 1995, 26, 171-176.

(Received: June 7, 2004)

(Revised: January 11, 2005)

(Accepted: January 12, 2005) 